\title{
Global Analysis of Research Trends on Kidney Function After Nephron-Sparing Surgery: A Bibliometric and Visualised Study
}

\author{
Faris Abushamma $\mathbb{D}^{1,2}$ \\ Abdulkarim Barqawi ${ }^{1,3}$ \\ Samah W Al-Jabi ${ }^{4}$ \\ Maha Akkawi ${ }^{1,5}$ \\ Mosab Maree (iD) ${ }^{1,6}$ \\ Sa'ed H Zyoud (iD) $4,7,8$
}

'Department of Medicine, College of Medicine and Health Sciences, An-Najah National University, Nablus, 44839, Palestine; ${ }^{2}$ Department of Urology, AnNajah National University Hospital, Nablus, 44839, Palestine; ${ }^{3}$ Department of General Surgery, An-Najah National University Hospital, Nablus, 44839, Palestine; ${ }^{4}$ Department of Clinical and Community Pharmacy, College of Medicine and Health Sciences, An-Najah National University, Nablus, 44839, Palestine; ${ }^{5}$ Department of Pathology, AnNajah National University Hospital, Nablus, 44839, Palestine; ${ }^{6}$ Department of Radiology, An-Najah National University Hospital, Nablus, 44839, Palestine;

${ }^{7}$ Poison Control and Drug Information Center (PCDIC), College of Medicine and Health Sciences, An-Najah National University, Nablus, 44839, Palestine; ${ }^{8}$ Clinical Research Center, An-Najah National University Hospital, Nablus, 44839, Palestine

Correspondence: Faris Abushamma Department of Medicine, College of Medicine and Health Sciences, An-Najah National University, Nablus, 44839, Palestine

Email farisabushamma@hotmail.com
Background: Nephron-sparing surgery (NSS) for small renal masses (SRMs) is currently the standard of care to treat renal cell carcinoma (RCC). The concept of partial resection of RCC has mainly been developed to preserve kidney function. Therefore, we have performed this study to explore the research activity that has been undertaken since the early twentyfirst century to investigate the advantages of NSS on preserving kidney function and preventing chronic kidney disease (CKD).

Methods: Based on the Scopus database, this bibliometric study was used to reveal publication patterns in the kidney function and NSS research field. The data were analysed with VOSviewer version 1.6.16 software, which was used to create a network visualisation map that included research hotspots in this area.

Results: A total of 449 scientific publications focused on renal function in NSS between 2001 and 2020. One hundred and seventy (38\%) of the total published articles originated from the USA. Journal of Urology, European Urology, and Journal of Endourology were the top publications detailing research in this field. Half (50\%) of the top 10 cited articles were published in the Journal of Urology, with an average citation of around 200 per article. The three most encountered research themes were comparative studies between partial and radical nephrectomy in terms of kidney function and development of CKD, the impact of type and duration of ischemia during resection on glomerular filtration rate (GFR) decline, and the effect of different surgical approaches on intermediate and long-term kidney function.

Conclusion: NSS for SRMs and RCC and its impact on kidney function is a hot topic in the literature, and the amount of published data has consistently been rising since 2000 . However, even though hundreds of documents have studied this topic from various perspectives, there is a compelling need to answer several questions such as the overall survival (OS) benefit of performing NSS in localised RCC and head-to-head comparison of robotic-assisted versus laparoscopic NSS in terms of warm ischemia time and long-term decline in GFR.

Keywords: nephron-sparing surgery, partial nephrectomy, kidney function, renal insufficiency, bibliometric, Scopus

\section{Introduction}

Nephron sparing surgery (NSS) has become the standard of care to treat small renal masses, which are the most prevalent type of renal cell carcinoma (RCC). ${ }^{1}$ The American Association of Urology (AUA) and European Association of Urology (EAU) guidelines recommend partial nephrectomy $(\mathrm{PN})$ surgery for small renal masses (SRMs). ${ }^{2,3}$ The established concept of PN to deal with RCC is mainly driven by the advantage of preserving kidney tissue to decrease the risk of future chronic 
kidney disease (CKD) and is now extended to include larger RCC. ${ }^{4}$ Several studies have investigated the oncological and functional outcome of NSS in comparison to radical nephrectomy (RN), which showed equivalent oncological outcomes, but questionable benefit on long-term kidney function and CKD. ${ }^{4-7}$ Furthermore, surgically induced kidney injuries are shown to have a less adverse effect on longterm kidney function. ${ }^{7-9}$

Moreover, the mortality associated with surgically induced kidney injury is not substantial during intermediateterm follow-up. ${ }^{9}$ The other debatable benefit of NSS is to decrease the potential development of cardiovascular disease (CVD), which may evolve secondary to CKD and lead to increased overall mortality. ${ }^{10}$ It is evident that CKD creates potential harm to the cardiovascular system and this in turn may lead to heart failure, arrhythmias, and potentially sudden cardiac death. ${ }^{11}$ Thus, theoretically, NSS should decrease CKD prevalence, heart-related complications, and improve overall survival (OS). These claimed advantages of NSS were supported by a comparative study that analysed the risk of CVD between $\mathrm{RN}$ and $\mathrm{PN}$ for RCC, which showed that RN was associated with worse overall mortality and cardiovascular mortality. ${ }^{12}$ However, the claimed heart-protective feature of NSS was queried recently by Capitanio et al, as their study showed no extra benefit of NSS on major cardiovascular events. ${ }^{13}$ Thus, future prospective and RCTs are required to investigate potential heart protective features of NSS during longterm follow-up. ${ }^{14}$

The benefits of cold versus warm ischemia during NSS also has been a trending question over the last few years in the prospect of kidney injury and long-term renal function. ${ }^{15}$ It is not apparent whether the type of ischemia directly impacts renal function; however, long-term function is linked to the quantity and quality of residual renal parenchyma rather than the duration or type of warm ischemia. Moreover, the surgical approach itself plays a significant role in ischemia duration and residual kidney parenchyma. ${ }^{16,17}$ We have decided to undertake this bibliometric analysis in order to examine the above listed queries and to show the trend of research activities.

\section{Methods}

\section{Data Source}

We used the Scopus database as a data source in this study, which is widely recognized as a reliable source for academic and bibliometric research. ${ }^{18,19}$

\section{Search Strategy}

To find applicable literature on kidney function and NSS from the last two decades (from January 2001 to December 31, 2020), we use the Scopus online database's "Advanced search" feature and enter the related keywords in the title. Data was collected on January 11, 2021. The following search strategy was used:

Step 1: The terms related to NSS that were entered into the Scopus engine were selected from the literature related to NSS in order to achieve the goals of this bibliometric study. ${ }^{20-22}$ All of the following terms were used in the article title: "Partial nephrectomy" OR "Nephron sparing surgery" OR "Nephron-Sparing Surgery" OR "enucleation".

Step 2: Following that, we restricted the publications retrieved in Step 1 to those with the term related to kidney failure in their titles. Kidney failure-related words were extracted from PubMed's Medical Subject Headings (MeSH) database and entered into the Scopus search engine. All of the following terms were entered in the article title: renal insufficiency, kidney insufficiency, kidney injury, kidney failure, kidney disease, renal disease, renal failure, ESRD, renal injury, creatinine, glomerular filtration rate, renal function, kidney function, haemodialysis, dialysis, warm ischemia, cold ischemia, ischaemia time, kidney filtration rate, and renal filtration rate.

\section{Bibliometric Analysis}

The basic information of each document was gathered, such as year of publication for articles, journals with their impact factors, countries, institutions, and top cited articles.

\section{Visualise Analysis}

In this analysis, VOSviewer software version 1.6.16 was used, which is a free software tool for creating and visualising bibliometric maps. ${ }^{23,24}$ To assess the hotspots for frontier studies, VOSviewer was used to construct network visualisation maps of the most co-occurring terms in the title and abstract.

\section{Ethics Approval}

Approval of an ethics committee was not necessary since this study was a bibliometric analysis with no human subjects.

\section{Results}

\section{Volume and Types of Publications}

A total of 4342 documents referencing NSS in the title were published between 2001 and 2020 at the global level. There 
were 449 scientific publications focused on renal function in NSS. An article was the main type of document for publications related to renal function in NSS, accounting for 77.51 $(n=348)$ of documents followed by notes $(n=44 ; 9.80)$, letters $(n=16 ; 3.56 \%)$; reviews $(n=14 ; 3.12 \%)$, and editorials $(13 ; 2.90 \%)$. Fourteen $(3.12 \%)$ publications were other types of documents such as conference papers or errata.

\section{Growth Research Analysis}

There has been a constant increase in publications focussing on NSS since 2000, as shown in Figure 1. Consequently, the understanding of the correlation between NSS and the effect on kidney function has also been steadily increasing since 2000. For example, in 2001, there were 50 published documents available regarding NSS. However, almost none of the reports were evaluating the impact of NSS on kidney function. In 2002, a jump in published papers discussing the relationship between NSS and kidney function, extended to 50 articles. In 2010, the amount of published data that discussed NSS in general, was roughly equal to the data investigating the relation between NSS and kidney function, which was around 200 articles each. In 2020, the amount of published data approximately doubled to exceed 350 articles.

\section{Top 10 Institutions and Countries}

The USA was the leading contributor to research on NSS and its impact on kidney function. One hundred and seventy (38\%) of the total published articles between 2001 and 2020 originated from the USA (Table 1). This representation mainly corresponds to the top USA medical institutions that participated actively in this field, as shown in Table 2. Cleveland Clinic Foundation, Memorial Sloan-Kettering Cancer Center, and Mayo Clinic are on the top of the list with a total of 82 (18\%) combined published articles. Cleveland Clinic Foundation is the leading institution with 44 (10\%) published articles in this field. This is followed by Memorial SloanKettering Cancer Center with 25 (6\%) published articles.

\section{Top Productive Journals and Most Cited Articles}

Journal of Urology, European Urology, and Journal of Endourology have led the research in this field since 2000. Journal of Urology has published 56 (12\%)

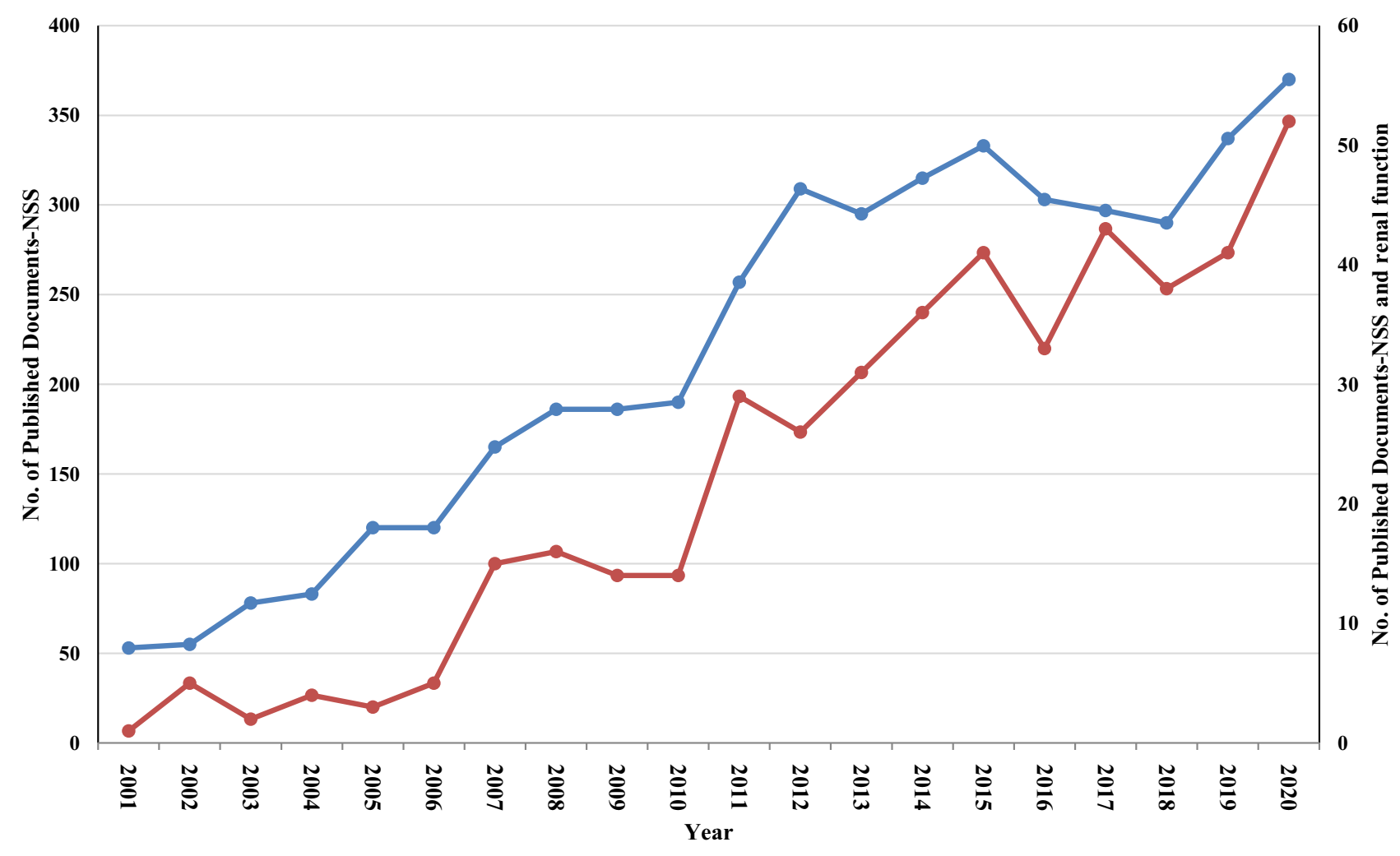

- No. of Published Documents-NSS $\quad-$ No. of Published Documents-NSS and renal function

Figure I The annual number of publications related to nephron-sparing surgery and renal function in nephron-sparing surgery research from $200 \mathrm{I}$ to 2020. 
Table I Top 10 Most Active Countries in Nephron-Sparing Surgery Research on Renal Function, as Measured by the Total Number of Publications Over the Last Two Decades (200I-2020)

\begin{tabular}{|l|c|c|c|}
\hline Ranking & Country & Number of Documents & $\%$ \\
\hline Ist & United States & 170 & 37.86 \\
2nd & South Korea & 48 & 10.69 \\
3rd & Japan & 47 & 10.47 \\
4th & Italy & 42 & 9.35 \\
5th & China & 37 & 8.24 \\
6th & Germany & 27 & 6.01 \\
7th & Canada & 19 & 4.23 \\
7th & Turkey & 19 & 4.23 \\
9th & France & 18 & 4.01 \\
10th & Spain & 12 & 2.67 \\
\hline
\end{tabular}

documents on NSS and kidney function (Table 3). Furthermore, $50 \%$ of the top 10 cited articles were published in the Journal of Urology, with an average citation of around 200 citations per article $6,15,25-32$ (Table 4). European Urology is the second on the list of the top 10 most productive journals in this field since 2000. Moreover, the second and third most cited articles in NSS and kidney function were published in European Urology as Backer et al published article had 289 citations and Scosyrev et al had 283 total citations. ${ }^{6,25}$ Urology Journal is the fifth on the top 10 list as it contributed to $33(7 \%)$ published articles. However, the top-cited article was published in Urology Journal by McKiernan et al with 434 citations.

\section{NSS and Kidney Function Test Most Encountered Topics and Themes}

The visualisation of the networks most often found terms in the title and abstract of the retrieved publications (minimum of 20 incidents) yielded three major colour clusters (ie, red, green, and blue) (Figure 2). These topics showed the most encountered and published keywords that researchers worked on over the last twenty years to establish the relationship between NSS and the impact on

Table 2 Top 10 Most Active Institutions in Nephron-Sparing Surgery Research on Renal Function, as Measured by the Total Number of Publications Over the Last Two Decades (200I-2020)

\begin{tabular}{|l|c|c|c|c|}
\hline Ranking & Institute & Country & Number of Publications & $\%$ \\
\hline Ist & Cleveland Clinic Foundation & USA & 44 & 9.80 \\
2nd & Memorial Sloan-Kettering Cancer Center & USA & 25 & 5.57 \\
3rd & IRCCS San Raffaele Scientific Institute & Italy & 15 & 3.34 \\
4th & Mayo Clinic & USA & 13 & 2.90 \\
4th & Tokyo Women's Medical University & Japan & 13 & 2.90 \\
6th & University of Ulsan, College of Medicine & South Korea & 12 & 2.67 \\
7th & Università Vita-Salute San Raffaele & Italy & 1 I & 2.45 \\
7th & Università degli Studi di Torino & Italy & 1 . & 2.45 \\
7th & Yonsei University College of Medicine & South Korea & 11 & 2.45 \\
10th & Asan Medical Center & South Korea & 10 & 2.23 \\
\hline
\end{tabular}

Table 3 Top 10 Most Active Journals in Nephron-Sparing Surgery Research on Renal Function, as Measured by the Total Number of Publications Over the Last Two Decades (200I-2020)

\begin{tabular}{|l|c|c|c|c|}
\hline Ranking & Journal & Number of Publications & $\%$ & IF $^{\mathbf{a}}$ \\
\hline Ist & Journal of Urology & 56 & 12.47 & 5.925 \\
2nd & European Urology & 47 & 10.47 & 17.947 \\
3rd & Journal of Endourology & 35 & 7.80 & 2.322 \\
4th & International Journal of Urology & 34 & 7.57 & 2.445 \\
5th & Urology & 33 & 7.35 & 1.924 \\
6th & BJU International & 24 & 5.35 & 4.806 \\
7th & World Journal of Urology & 17 & 3.79 & 3.217 \\
8th & Urologic Oncology Seminars and Original Investigations & 14 & 3.12 & 2.882 \\
9th & International Urology and Nephrology & 13 & 2.90 & 2.445 \\
10th & Urologia Internationalis & 8 & 1.78 & 1.698 \\
\hline
\end{tabular}

Note: ${ }^{a}$ Impact factor (IF) based on Journal Citation Reports (JCR) 2019 from Clarivate Analytics. 
Table 4 Top 10 Most Cited Documents on Renal Function in Nephron-Sparing Surgery Research, Ranked by the Total Number of Publications Over the Last Two Decades (200I-2020)

\begin{tabular}{|c|c|c|c|c|}
\hline Ranking & Authors & Year & Source Title & Cited by \\
\hline Ist & McKiernan et $\mathrm{al}^{29}$ & 2002 & Urology & 434 \\
\hline 2nd & Becker et $\mathrm{al}^{25}$ & 2009 & European Urology & 289 \\
\hline $3 r d$ & Scosyrev et $\mathrm{al}^{6}$ & 2014 & European Urology & 283 \\
\hline 4th & Kim et $\mathrm{al}^{28}$ & 2012 & Journal of Urology & 262 \\
\hline 5 th & Lane et $\mathrm{al}^{15}$ & 2011 & Journal of Urology & 260 \\
\hline 6th & Thompson et $\mathrm{al}^{32}$ & 2012 & Urology & 239 \\
\hline 7th & Desai et $\mathrm{a}^{26}$ & 2005 & BJU International & 178 \\
\hline 8th & Janetschek et $\mathrm{al}^{27}$ & 2004 & Journal of Urology & 160 \\
\hline 9th & Mir et $\mathrm{al}^{30}$ & 2015 & Journal of Urology & 152 \\
\hline 10th & Simmons et $\mathrm{al}^{31}$ & 2011 & Journal of Urology & 145 \\
\hline
\end{tabular}

kidney function. The red cluster shows the comparative studies of PN and RN in glomerular filtration rate (GFR) decline and CKD development. The blue cluster shows the type of ischemia and its impact on kidney function. Finally, the green cluster shows the different surgical approaches in the prospect of the type and duration of ischemia, and its effect on long-term kidney function. These three topics have been trending over the last twenty years in order to establish the effectiveness of NSS and determinants that play a significant role in preserving kidney function during NSS, such as surgical approach, type, and time of ischemia.

\section{Discussion}

The current study aimed to evaluate the scientific literature on kidney function after NSS for RCC. Since the

\section{VOSviewer}

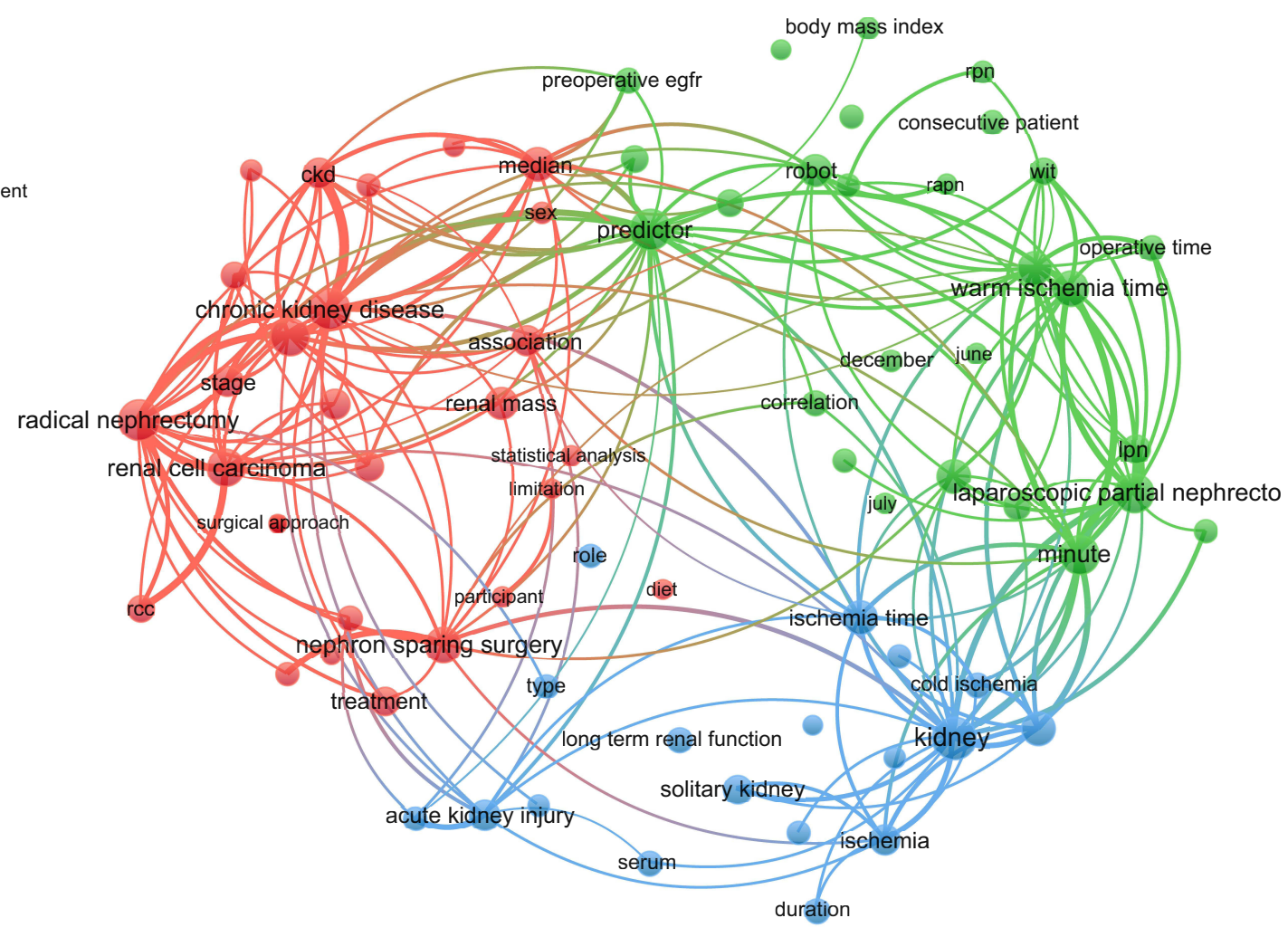

Figure 2 Network visualisation map of terms in the title/abstract fields of publications related to renal function in nephron-sparing surgery from 200I to 2020. When the minimum term occurrences were placed at least 20 times, a visualized map of terms was generated. Out of 7049 terms in this area, 121 met this criterion, which were divided into three clusters and coloured differently. The node's size indicates the number of publications that use that term. 
beginning of the twenty-first century, several published articles have confirmed the safety and efficacy of open and minimally invasive NSS. ${ }^{33-35}$ However, since then, researchers have been trying to prove the claimed theoretical benefit of NSS on kidney function and OS.

The analysis showed that the research activities were focused around three topics or themes. Those topics are colour coded as shown in Figure 2, with strong association. The red cluster shows that the researchers' effort was mainly to compare RN and PN in the prospect of chronic kidney disease. McKiernan et al published the top-cited article in 2002 with more than 400 citations, which retrospectively compared $\mathrm{RN}$ and $\mathrm{PN}$ in view of the impact on kidney function. The article concluded that RN patients were at higher risk of developing renal failure over time. ${ }^{29}$ On the other hand, the EORTC group published RCTs in 2014 comparing $\mathrm{RN}$ and $\mathrm{PN}$ in regards to developing renal failure and advanced kidney disease over 6.7 years followup, which showed similar rates of progressive kidney disease and end-stage renal failure between the two groups. ${ }^{6}$ Surprisingly, the EORTC trial showed that the potential benefit of reducing moderate renal failure (eGFR $<60 \mathrm{ml} / \mathrm{min} / 1.73 \mathrm{~m}^{3}$ ) was not reflected on OS. ${ }^{6}$ Thus, the theoretical advantage of preserving kidney function in NSS did not improve OS, which was the cornerstone concept of adapting NSS in RCC. Such conflicting results raise a question regarding the heart protective advantage of NSS as it is known that renal impairment is usually associated with CVD. Several articles showed that NSS decreased the risk of developing CVD. ${ }^{36,37}$ However, another set of published scientific data showed the heartprotective features of NSS were age-related and NSS has no benefit in reducing major cardiovascular events. ${ }^{38}$ Lastly, the OS potential benefit of NSS, which may be attributed to either better kidney function or less CVD, was not clearly found in an RCT published in 2011 by Van Poppel et al..$^{5}$ Thus, the debatable positive impact of NSS on OS is still not clearly evident, and future prospective and comparative studies are required to determine this advantage.

The blue cluster shows the researchers' interest in the type of intraoperative renal ischemia during NSS and its impact on kidney function. Lane et al published an article in 2011 in the Journal of Urology comparing cold and warm ischemia times in 660 solitary kidneys and its impact on ultimate renal function. At 3 months, the median GFR decreased to a similar amount with cold and warm ischemia. ${ }^{15}$ However, other independent variables such as tumour size, low baseline kidney function, and longer ischemia time were associated with poor long-term, post-operative kidney function. Warm ischemia time was acceptable up to 30 minutes with minimal decline in GFR postoperatively. ${ }^{26}$ Furthermore, Janetschek et al showed that laparoscopic PN in cold ischemia was an alternative and feasible way of resecting SRMs with a median resection time of 40 minutes (27-101). Thus, both warm and cold ischemia whilst artery-clamping are acceptable ways to achieve oncologically proper resection of RCC with relatively similar resection time and minimal effect on GFR if resection was completed within an appropriate timescale.

The green cluster shows the different surgical approaches of NSS in relation to the impact on kidney function. Additionally, the duration of ischemia was also investigated between different surgical modalities. The results are variable based on surgeon experience, the complexity of the tumour, and the type of ischemia during artery-clamping. Becker et al showed that warm ischemia up to 20 minutes and cold ischemia up to 2 hours were unlikely to be associated with ischemia-induced kidney injury. ${ }^{25}$ The duration of ischemia is variable based on surgical technique, which may affect the overall postoperative kidney function based on the surgical procedure. For instance, several published articles confirmed that warm ischemia time is shorter in the open approach than a laparoscopic approach. This is reflected in less decline in GFR postoperatively; however, this is not reflected in longer-term CKD. ${ }^{39,40}$

However, a single prospective study that compared the perioperative outcomes of open and robotic-assisted PN showed equivalent warm ischemia time and decline in GFR. ${ }^{41}$ Minimally invasive NSS appeared not to harm long-term kidney function. Therefore, minimally invasive NSS is now the standard of care to treat SRMs. Roboticassisted NSS seemed to provide the best preservation of kidney parenchyma; although BMI, warm ischemic time (WIT), and baseline kidney function are the major factors that influence the postoperative kidney function after NSS. ${ }^{42}$ A meta-analysis was done to compare laparoscopic and robotic-assisted NSS, which showed that roboticassisted NSS had shorter warm ischemic time and less drop in GFR postoperatively. However, these findings were not reflected in serum creatinine change over time. $^{21}$ Thus, a randomized clinical trial is still required to establish such differences and other perioperative parameters between different types of minimally invasive NSS. 


\section{Strength and Limitations}

This is the first bibliometric analysis of its kind to look into this subject and provide comprehensive information on research trends and developments in this emerging field. However, there are several limitations similar to previous bibliometric studies that are necessary to remember. ${ }^{43-45}$ Firstly, the publications were retrieved from the Scopus database between 2001 and 2020, which does not adequately cover all topics pertaining to NSS and kidney function research. Therefore, grey literature and publications in nonindexed journals have not been studied. Secondly, the current study was limited to the search terms "NSS", "kidney function" and related terms in the title search only. Any publications that used "NSS" and "kidney function" as a keyword or within the publication may have been missed in this analysis. Despite these limitations, this bibliometric study offers a fairly comprehensive overview of "NSS" and "kidney function" studies over the last two decades.

\section{Conclusions}

NSS for SRMs and RCC and its impact on kidney function is a trending topic in the literature, with hundreds of articles published. The most encountered themes are comparing RN to $\mathrm{PN}$ in terms of post-op and long-term CKD, the impact of type and duration of ischemia during PN on GFR, and different surgical approaches in relation to the duration of ischemia and development of CKD. In addition, there is still an evidence-free area regarding the OS benefit of performing NSS in localized RCC and head-to-head comparison of robotic-assisted versus laparoscopic NSS in terms of warm ischemia time and long-term decline GFR.

\section{Acknowledgment}

The authors thank Samantha Kearley from the Bristol Urological Institute, UK, for English editing of the manuscript.

\section{Author Contributions}

All authors made substantial contributions to the conception and design, acquisition of data, or analysis and interpretation of data; took part in drafting the article or revising it critically for important intellectual content; agreed to submit to the current journal; gave final approval of the version to be published; and agree to be accountable for all aspects of the work.

\section{Funding}

No specific grant was received from any public, commercial, or non-profit funding agency for this research.

\section{Disclosure}

The authors report no conflicts of interest for this work.

\section{References}

1. Kato M, Suzuki T, Suzuki Y, Terasawa Y, Sasano H, Arai Y. Natural history of small renal cell carcinoma: evaluation of growth rate, histological grade, cell proliferation and apoptosis. $J$ Urol. 2004;172(3):863-866. doi:10.1097/01.ju.0000136315.80057.99

2. Campbell S, Uzzo RG, Allaf ME, et al. Renal mass and localized renal cancer: AUA guideline. J Urol. 2017;198(3):520-529. doi:10. 1016/j.juro.2017.04.100

3. Chenam A, Lau C. Management of small renal masses. Cancer Treat Res. 2018;175:105-126. doi:10.1007/978-3-319-93339-9_5

4. Amparore D, Pecoraro A, Piramide F, et al. Comparison between minimally-invasive partial and radical nephrectomy for the treatment of clinical T2 renal masses: results of a 10-year study in a tertiary care center. Minerva Urol Nephrol. 2021;73(4). doi:10.23736/s27246051.21.04390-1

5. Van Poppel H, Da Pozzo L, Albrecht W, et al. A prospective, randomised EORTC intergroup Phase 3 study comparing the oncologic outcome of elective nephron-sparing surgery and radical nephrectomy for low-stage renal cell carcinoma. Eur Urol. 2011;59 (4):543-552. doi:10.1016/j.eururo.2010.12.013

6. Scosyrev E, Messing EM, Sylvester R, Campbell S, Van Poppel H. Renal function after nephron-sparing surgery versus radical nephrectomy: results from EORTC randomized trial 30904. Eur Urol. 2014;65(2):372-377. doi:10.1016/j.eururo.2013.06.044

7. Akpinar C, Dogan O, Kubilay E, et al. The evaluation of acute kidney injury due to ischemia by urinary neutrophil gelatinase-induced lipocalin (uNGAL) measurement in patients who underwent partial nephrectomy. Int Urol Nephrol. 2021;53(3):393-400. doi:10.1007/ s11255-020-02660-2

8. Antonelli A, Allinovi M, Cocci A, et al. The predictive role of biomarkers for the detection of acute Kidney injury after partial or radical nephrectomy: a systematic review of the literature. Eur Urol Focus. 2020;6(2):344-353. doi:10.1016/j.euf.2018.09.020

9. Lane BR, Campbell SC, Demirjian S, Fergany AF. Surgically induced chronic kidney disease may be associated with a lower risk of progression and mortality than medical chronic kidney disease. J Urol. 2013;189(5):1649-1655. doi:10.1016/j.juro.2012.11.121

10. Palacios DA, Zabor EC, Munoz-Lopez C, et al. Does reduced renal function predispose to cancer-specific mortality from renal cell carcinoma? Eur Urol. 2021;79(6):774-780. doi:10.1016/j.eururo.20 21.02 .035

11. Di Lullo L, House A, Gorini A, Santoboni A, Russo D, Ronco C. Chronic kidney disease and cardiovascular complications. Heart Fail Rev. 2015;20(3):259-272. doi:10.1007/s10741-014-9460-9

12. Kates M, Badalato GM, Pitman M, McKiernan JM. Increased risk of overall and cardiovascular mortality after radical nephrectomy for renal cell carcinoma $2 \mathrm{~cm}$ or less. J Urol. 2011;186(4):1247-1253. doi:10.1016/j.juro.2011.05.054

13. Capitanio U, Larcher A, Cianflone F, et al. Hypertension and cardiovascular morbidity following surgery for kidney cancer. Eur Urol Oncol. 2020;3(2):209-215. doi:10.1016/j.euo.2019.02.006

14. Breau RH, Kapoor A, Nash DM, et al. Partial vs. radical nephrectomy and the risk of all-cause mortality, cardiovascular, and nephrological outcomes. Can Urol Assoc J. 2020;14(10):337-345. doi:10. 5489/cuaj.6436 
15. Lane BR, Russo P, Uzzo RG, et al. Comparison of cold and warm ischemia during partial nephrectomy in 660 solitary kidneys reveals predominant role of nonmodifiable factors in determining ultimate renal function. $J$ Urol. 2011;185(2):421-427. doi:10.1016/j.juro.20 10.09.131

16. Rod X, Peyronnet B, Seisen T, et al. Impact of ischaemia time on renal function after partial nephrectomy: a systematic review. BJU Int. 2016;118(5):692-705. doi:10.1111/bju.13580

17. Faria EF, Caputo PA, Wood CG, Karam JA, Nogueras-González GM, Matin SF. Robotic partial nephrectomy shortens warm ischemia time, reducing suturing time kinetics even for an experienced laparoscopic surgeon: a comparative analysis. World J Urol. 2014;32(1):265-271. doi:10.1007/s00345-013-1115-2

18. Baas J, Schotten M, Plume A, Côté G, Karimi R. Scopus as a curated, high-quality bibliometric data source for academic research in quantitative science studies. Quant Sci Stud. 2020;1(1):377-386. doi:10. 1162/qss_a_00019

19. Sweileh WM. Bibliometric analysis of scientific publications on "sustainable development goals" with emphasis on "good health and well-being” goal (2015-2019). Global Health. 2020;16(1):68. doi:10.1186/s12992-020-00602-2

20. Vanden Berg RN, Bierman EN, Noord MV, Rice HE, Routh JC. Nephron-sparing surgery for Wilms tumor: a systematic review. Urol Oncol. 2016;34(1):24-32. doi:10.1016/j.urolonc.20 15.07.003

21. Choi JE, You JH, Kim DK, Rha KH, Lee SH. Comparison of perioperative outcomes between robotic and laparoscopic partial nephrectomy: a systematic review and meta-analysis. Eur Urol. 2015;67(5):891-901. doi:10.1016/j.eururo.2014.12.028

22. Xu J, Xu S, Yao B, et al. Segmental artery clamping versus main renal artery clamping in nephron-sparing surgery: updated meta-analysis. World J Surg Oncol. 2020;18(1):210. doi:10.1186/ s12957-020-01990-w

23. van Eck NJ, Waltman L. Software survey: vOSviewer, a computer program for bibliometric mapping. Scientometrics. 2010;84 (2):523-538. doi:10.1007/s11192-009-0146-3

24. van Eck NJ, Waltman L. Citation-based clustering of publications using CitNetExplorer and VOSviewer. Scientometrics. 2017;111 (2):1053-1070. doi:10.1007/s11192-017-2300-7

25. Becker F, Van Poppel H, Hakenberg OW, et al. Assessing the impact of ischaemia time during partial nephrectomy. Eur Urol. 2009;56 (4):625-634. doi:10.1016/j.eururo.2009.07.016

26. Desai MM, Gill IS, Ramani AP, Spaliviero M, Rybicki L, Kaouk JH. The impact of warm ischaemia on renal function after laparoscopic partial nephrectomy. BJU Int. 2005;95(3):377-383. doi:10.1111/ j.1464-410X.2005.05304.x

27. Janetschek G, Abdelmaksoud A, Bagheri F, Al-Zahrani H, Leeb K, Gschwendtner M. Laparoscopic partial nephrectomy in cold ischemia: renal artery perfusion. J Urol. 2004;171(1):68-71. doi:10.1097/ 01.ju.0000101040.13244.c4

28. Kim SP, Thompson RH, Boorjian SA, et al. Comparative effectiveness for survival and renal function of partial and radical nephrectomy for localized renal tumors: a systematic review and meta-analysis. J Urol. 2012;188(1):51-57. doi:10.1016/j.juro.2012. 03.006

29. McKiernan J, Simmons R, Katz J, Russo P. Natural history of chronic renal insufficiency after partial and radical nephrectomy. Urology. 2002;59(6):816-820. doi:10.1016/s0090-4295(02)01501-7

30. Mir MC, Ercole C, Takagi T, et al. Decline in renal function after partial nephrectomy: etiology and prevention. J Urol. 2015;193 (6):1889-1898. doi:10.1016/j.juro.2015.01.093
31. Simmons MN, Fergany AF, Campbell SC. Effect of parenchymal volume preservation on kidney function after partial nephrectomy. J Urol. 2011;186(2):405-410. doi:10.1016/j.juro.2011.03.154

32. Thompson RH, Lane BR, Lohse CM, et al. Renal function after partial nephrectomy: effect of warm ischemia relative to quantity and quality of preserved kidney. Urology. 2012;79(2):356-360. doi:10.1016/j.urology.2011.10.031

33. Lane BR, Gill IS. 7-year oncological outcomes after laparoscopic and open partial nephrectomy. $J$ Urol. 2010;183(2):473-479. doi:10.10 16/j.juro.2009.10.023

34. Patard JJ, Shvarts O, Lam JS, et al. Safety and efficacy of partial nephrectomy for all $\mathrm{T} 1$ tumors based on an international multicenter experience. J Urol. 2004;171(6 Pt 1):2181-2185, quiz 2435. doi:10.1097/01.ju.0000124846.37299.5e

35. Iizuka J, Kondo T, Hashimoto Y, et al. Similar functional outcomes after partial nephrectomy for clinical $\mathrm{T} 1 \mathrm{~b}$ and $\mathrm{T} 1 \mathrm{a}$ renal cell carcinoma. Int J Urol. 2012;19(11):980-986. doi:10.1111/j.14422042.2012.03085.x

36. Huang WC, Elkin EB, Levey AS, Jang TL, Russo P. Partial nephrectomy versus radical nephrectomy in patients with small renal tumorsis there a difference in mortality and cardiovascular outcomes? $J$ Urol. 2009;181(1):55-61; discussion 61-52. doi:10.1016/j. juro.2008.09.017

37. Miller DC, Schonlau M, Litwin MS, Lai J, Saigal CS. Renal and cardiovascular morbidity after partial or radical nephrectomy. Cancer. 2008;112(3):511-520. doi:10.1002/cncr.23218

38. Sun M, Becker A, Tian Z, et al. Management of localized kidney cancer: calculating cancer-specific mortality and competing risks of death for surgery and nonsurgical management. Eur Urol. 2014;65(1):235-241. doi:10.1016/j. eururo.2013.03.034

39. Marszalek M, Meixl H, Polajnar M, Rauchenwald M, Jeschke K, Madersbacher S. Laparoscopic and open partial nephrectomy: a matched-pair comparison of 200 patients. Eur Urol. 2009;55 (5):1171-1178. doi:10.1016/j.eururo.2009.01.042

40. Muramaki M, Miyake H, Sakai I, Fujisawa M. Prognostic factors influencing postoperative development of chronic kidney disease in patients with small renal tumors who underwent partial nephrectomy. Curr Urol. 2013;6(3):129-135. doi:10.1159/000343526

41. Masson-Lecomte A, Yates DR, Hupertan V, et al. A prospective comparison of the pathologic and surgical outcomes obtained after elective treatment of renal cell carcinoma by open or robot-assisted partial nephrectomy. Urol Oncol. 2013;31(6):924-929. doi:10.1016/j. urolonc.2011.08.004

42. Zargar H, Akca O, Autorino R, et al. Ipsilateral renal function preservation after robot-assisted partial nephrectomy (RAPN): an objective analysis using mercapto-acetyltriglycine (MAG3) renal scan data and volumetric assessment. BJU Int. 2015;115(5):787-795. doi:10. 1111/bju. 12825

43. Sweileh WM, Moh'd Mansour A. Bibliometric analysis of global research output on antimicrobial resistance in the environment (2000-2019). Glob Health Res Policy. 2020;5(1):37. doi:10.1186/ s41256-020-00165-0

44. Zyoud SH, Al-Jabi SW. Mapping the situation of research on coronavirus disease-19 (COVID-19): a preliminary bibliometric analysis during the early stage of the outbreak. BMC Infect Dis. 2020;20 (1):561. doi:10.1186/s12879-020-05293-z

45. Zyoud SH, Smale S, Waring WS, Sweileh W, Al-Jabi SW. Global research trends in the microbiome related to irritable bowel syndrome: a bibliometric and visualized study. World J Gastroenterol. 2021;27(13):1341-1353. doi:10.3748/wjg.v27.i13.1341 


\section{Publish your work in this journal}

Cancer Management and Research is an international, peer-reviewed open access journal focusing on cancer research and the optimal use of preventative and integrated treatment interventions to achieve improved outcomes, enhanced survival and quality of life for the cancer patient.
The manuscript management system is completely online and includes a very quick and fair peer-review system, which is all easy to use. Visit http://www.dovepress.com/testimonials.php to read real quotes from published authors. 